\title{
Ciudad Fantasma: Prácticas Artísticas en Contextos de Pobreza Urbana de Buenos Aires
}

\section{Ghost City: Artistic Practices in Contexts of Urban Poverty in Buenos Aires}

\author{
Cintia Schwamberger * \\ Universidad de General San Martín, Argentina
}

\section{DESCRIPTORES:}

Educación artística

Discapacidad

Pobreza

Escuela

Justicia social

\section{RESUMEN:}

En el presente artículo presentamos resultados de investigación a través de una experiencia de educación artística en el marco de un taller de producción audiovisual realizado junto a un grupo de estudiantes con discapacidad en una escuela de educación especial emplazada en contexto de pobreza urbana en una localidad de la provincia de Buenos Aires. A través de un trabajo de investigación cualitativa recuperamos los relatos de estudiantes en torno al proceso de elaboración de un corto audiovisual que se sitúa en un marco de enunciación ante situaciones de contaminación y degradación ambiental en que transcurren las vidas en estos espacios de la metrópoli. Ciudad Fantasma, opera prima del grupo escolar, se presenta como un acto de denuncia ante las desigualdades interseccionales que vive el colectivo de estudiantes con discapacidad en estos contextos. A partir de resultados de investigación analizamos el modo en que las prácticas artísticas en educación permiten a estudiantes con discapacidad el desarrollo de competencias comunicativas que resultan muchas veces silenciadas. Proponemos que la educación artística se convierte en una herramienta fundamental para la problematización de las condiciones de vida como un modo de justicia social que permite a estudiantes cuestionar, de manera colectiva, su tiempo presente.

\section{KEYWORDS:}

Artistic education

Disability

Poverty

School

Social justice

\section{ABSTRACT:}

In this article we present research results through an artistic education experience in the framework of an audiovisual production workshop carried out with a group of students with disabilities in a special education school located in a context of urban poverty in a town of the province of Buenos Aires. Through a qualitative research work we recover the stories of students around the process of making an audiovisual short that is situated in a framework of enunciation in situations of pollution and environmental degradation in which lives pass in these spaces of the metropolis. Ciudad Fantasma, the school group's first film, is presented as an act of denunciation of the intersectional inequalities experienced by the group of students with disabilities in these contexts. Based on research results, we analyze the way in which artistic practices in education allow students with disabilities to develop communication skills that are often silenced. We propose that art education becomes a fundamental tool for the problematization of living conditions as a way of social justice that allows students to collectively question their present time.

CÓMO CITAR:

Schwamberger, C. (2021). Ciudad fantasma: Prácticas artísticas en contextos de pobreza urbana de Buenos Aires. Revista Internacional de Educación para la Justicia Social, 10(2), 75-90.

https://doi.org/10.15366/riejs2021.10.2.005

*Contacto: cintiaschwamberger@gmail.com

ISSN: 2254-3139

revistas.uam.es/riejs
Recibido:

15 de abril 2021

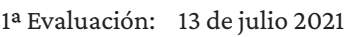

2a Evaluación: 29 de agosto 2021

Aceptado: 


\section{Introducción ${ }^{1}$}

Una imagen vale más que mil palabras, adagio que se utiliza para recuperar la complejidad de un mensaje mediante la producción de imágenes artísticas de distintas realidades sociales. En ese punto, entendemos que el uso de la imagen y en este caso la producción audiovisual se vuelven modos claves de indagación en las ciencias sociales, más específicamente al interior de la cotidianeidad escolar. Modos que resultan novedosos y que aportan a la comprensión del objeto de indagación de un modo múltiple y complejo. Estas herramientas promueven la producción de conocimiento, desde los protagonistas, así como la apertura para realizar y generar oportunidades pedagógicas que contribuyen a hacer cognoscible la experiencia escolar en territorios marcados por la desigualdad y la pobreza urbana como en la que se asienta la escuela donde realizamos el proyecto de investigación.

Este trabajo, ocurre en un marco de colaboración entre un equipo de investigación, docentes de la escuela especial y estudiantes con discapacidad intelectual, que procura problematizar distintos interrogantes vinculados a la vida cotidiana de cada uno de ellos. En particular, nos interesa analizar los enunciados producidos por los sujetos que intervienen en esta práctica artística escolar y que están directamente relacionados con el contexto social que viven. Sobre estas prácticas, nos adentramos en el desarrollo de un taller en una escuela de educación especial, en una localidad de la provincia de Buenos Aires, que aloja estudiantes con discapacidad intelectual que habitan los territorios más empobrecidos de la urbe. Espacios que, desde mediado del siglo pasado, no dejan de ver crecer sus índices poblacionales y condiciones de fragmentación (Prevot-Shapira, 2001), así como la extrema pobreza y la degradación ambiental (Grinberg, 2020). A partir de ello, nos interesa analizar el modo en que estudiantes con discapacidad se enuncian y producen discursos sobre sí mismos y sus barrios ante la mirada estigmatizante que sopesa sobre ellos (Ferrante, 2020).

Importa analizar lo que Inés Dussel (2006), en Educar la Mirada, propone que las imágenes se transforman en acontecimientos, y devienen efectos de producción de subjetividad en un marco de redes discursivas y relacionales. En ese sentido, la imagen captura y "congela" situaciones de las instituciones y de los sujetos que asisten a ella. En particular, permite el registro de aquello que muchas veces resulta imperceptible. La imagen, en tanto acontecimiento, opera en dos sentidos que se retroalimentan. Por un lado, elabora un discurso que permite reflexionar sobre la propia práctica escolar, a la vez, que desnaturaliza enunciados que circulan en los ámbitos sociales y en los medios de comunicación. Así, esta experiencia escolar de producción audiovisual se propone como un modo de denuncia y puesta en cuestión de las injusticias sociales que atraviesa el colectivo de estudiantes con discapacidad que viven en contexto de pobreza urbana de Buenos Aires.

En el primer apartado recuperamos algunos de los debates sobre la utilización de la producción de imágenes en los espacios educativos como modo múltiple de establecer justicia social (Murillo y Hernández, 2014), en los espacios más empobrecidos de la región. Seguidamente, nos centramos en la estrategia metodológica a través de la realización de un taller de producción audiovisual en el que estudiantes, docentes e investigadores se encuentran de manera colaborativa para crear procesos de producción de conocimiento y circulación de la palabra (Grinberg, 2012). Luego, nos adentramos en el material de análisis del trabajo de campo que propone la potencia que adquiere el uso de distintas técnicas artísticas en escuelas que alojan estudiantes con discapacidad intelectual y cómo ello se vuelve una práctica colectiva, a la vez, que una suspensión de los acontecimientos desiguales del mundo que los rodea.

\section{Revisión de la literatura}

Durante las últimas décadas, la utilización del lenguaje audiovisual, en los ámbitos escolares, ha ido ganando terreno como medio para indagar distintas prácticas sociales cotidianas (Grinberg y Abálsamo, 2016; Hickey-Moody, 2017; Langer et al., 2015; Sánchez-Aranegui, 2018) y como herramienta pedagógica

1 Ciudad Fantasma (2018), corto audiovisual presentado en la Feria de Ciencias Humanas y Sociales de la Universidad Nacional de San Martín que se puede visualizar en el siguiente enlace: https://www.youtube.com/ watch?v=WopjOnn29-I\&t=3s 
de expresión creativa (Carpentieri, Grinberg, Armella, 2020; Infante, 2018; Saura Pérez, 2015). Así, las prácticas artísticas en un marco social comprometido permiten producir nuevas formas de subjetividad grupal, como métodos intraactivos y difractivos (Hickey- Moody, 2012; Hickey- Moody y Proasi, 2021), a través de los cuales podemos establecer otros modos de ser y estar en el mundo, siempre, junto a otros (Grinberg y Armella, 2021). En este sentido, la producción audiovisual, visual y narrativa se vuelve una instancia de conocimiento, a la vez, que objeto de indagación y reflexión, ya que materializa los hechos sociales desde múltiples aristas e involucra "modos de pensamiento en acto" (Hickey-Moody y Page, 2015, p. 1). Algunos de estos modos, son los que recuperamos a través de relatos y discursos de los jóvenes mediante la producción de un corto audiovisual que retoma distintas líneas de interrogación y problematización de la vida en los barrios que habitan.

Asimismo, importa delinear aquí que las propuestas de producción audiovisual, cuando se trata de estudiantes con discapacidad intelectual, se vuelve clave, en el momento en que adquiere potencia, la posibilidad de enunciar y transmitir un mensaje, pensar un problema de investigación y abordarlo desde distintas perspectivas, más aún, cuando, en oportunidades, para expresar sus deseos, experiencias y situaciones complejas de vida, el uso del lenguaje oral hegemónico encuentra sus alternancias. Nos referimos en este caso, cuando efectivamente allí, para expresar(se) se explora la posibilidad de construir y elaborar mensajes y palabras a través de modos otros: como el cuerpo, los gestos, los rostros, los dibujos, los ruidos, los movimientos, las imágenes, entre otros.

Donde la palabra y la oralidad se encuentran "suspendidas", la educación en el arte y la producción audiovisual se transforman en una herramienta fundamental, tanto en la investigación como en la propuesta pedagógica escolar, para poner en cuestión los modos normalizados de ser y estar en el mundo. En ese sentido proponemos junto con Hickey-Moody (2012) que:

El arte tiene una capacidad política efectiva, la capacidad de reelaborar los límites de un cuerpo, de reconfigurar arreglos individuales de estructura/agencia, de aumentar lo que un cuerpo es capaz de comprender, producir y al cual podría conectarse. (p. 11)

Encontrarse en esa potencia incalculable y contingente de capacidad de los cuerpos (Mc Ruer, 2020), a través del arte y posicionarse políticamente, es aquello que discutimos aquí. Realizar distintas investigaciones educativas mediante procesos artísticos, a través de talleres de creación audiovisual, permite maximizar el potencial de las habilidades comunicativas, tanto verbales como no verbales, así como los modos en que el grupo estudiantil establece relaciones entre sí, junto a sus docentes y los integrantes del equipo de investigación como con los materiales que se utilizan. De acuerdo a Hickey-Moody (2017),

Los talleres generan un conjunto de datos innovadores que incluyen imágenes creadas por jóvenes, videos y fotografías (...) que ofrecen un valor incalculable de la visión política encarnada a través de la creación artística y las relaciones interpersonales que allí se suscitan. (p. 1084)

Asimismo, creemos junto a Nussbaum (2012), que la educación a través y por el arte, permite desplegar y potenciar las capacidades de los grupos estudiantiles que participan de estas propuestas. No sólo ello, sino, que, fundamentalmente propone procesos de reafirmación de las identidades en tanto se tornan sujetos políticos y de enunciación de las desigualdades e injusticias sociales que viven. Como menciona Saura-Pérez (2015),
(...) la enseñanza y aprendizaje artístico pueden y deben aportar un camino alternativo a las tendencias globalizadoras que cada vez se imponen con más fuerza en nuestra sociedad (...), es necesario que la educación en general y el arte en particular, fomente desde las aulas el pensamiento divergente y crítico de los estudiantes y su capacidad de discernir y de ser sensibles ante los acontecimientos sociales que nos conciernen. (p. 771)

La posibilidad de desplegar distintas experiencias artísticas como eje transversal a contenidos curriculares y áreas disciplinares, como es el caso del taller que recuperamos, permite posicionar al grupo de estudiantes ante ese ojo crítico y necesario para intentar reponer los fundamentos de una escuela y una sociedad más justa, menos desigual y menos excluyente (Murillo y Hernández, 2014). Empero ello, importa interrogarnos, "¿Cómo vinculamos los aprendizajes de los estudiantes para que consideren una posible transferencia en ese mundo que no es la escuela pero que se encuentra allí suspendido tan solo 
por un momento?" (Masschelein y Simons, 2014, p. 54). Allí, el cuerpo docente piensa ese mundo y logra hacerlo cognoscible para sus estudiantes, con distintas herramientas, metodologías diversas y recursos múltiples que les permite acercarse un poco más al conocimiento, a la cultura, y por qué no, a vivir junto a otros la experiencia de la vida. En ese punto Redondo (2016) nos recuerda que,

La existencia de un mundo que se profundiza o amplía nos invita a pensar en una escuela que va más allá de la escuela, que se abre al mundo... o que abre otros mundos para la escuela en la propia escuela. (p. 187)

En este sentido, la escuela abre otros mundos que van más allá de la propia materialidad de la escuela e intenta bucear en nuevos caminos para dar a conocer lo que sucede y lo que se transforma en su interior. En esa transformación del mundo, las imágenes, en este caso, producidas por estudiantes, como refiere Arfuch (2006), revelan una potencia creadora, instituyente y persuasiva. Pero también, como menciona Barthes (2003), en esta construcción hay algo que allí incomoda. Es el puntcum (p. 59) que nos despunta, que nos desestabiliza, que no produce ningún agrado, sino su efecto contrario. Es esa imagen que provoca conmoción, perplejidad y dolor. Imágenes que por cierto se construyen a partir de las injusticias sociales del presente desolador que experimentamos. Son esas formas que, también, constituyen modos de contemplación del mundo que nos rodea (Arfuch, 2006) y, que ofrece "una dimensión sensorial que ha sido tradicionalmente ignorada en la disciplina” (Cabrera y Guarín, 2012, p. 19) y permite transitar o, más bien, acceder a la mirada de quien investiga pero también junto a quién se hace investigación.

En esta trama, Didi-Huberman (2008), en sus estudios sobre el arte y la pedagogía, establece que este vínculo se conjuga mediante luchas, tensiones y disputas, entre dispositivos de poder en el que la potencia de la narración, a través de las imágenes, "se presenta como posibilidad de ensayar nuevas formas de la pedagogía, de volver permeables los límites de la escuela, de alojar narraciones, relatos que nos despunten" (Schwamberger, et al., 2020, p. 79), y logren dimensionar las condiciones en que las desigualdades son moneda corriente en los espacios que habitamos (Grinberg, 2020). Por tanto, sostenemos que la educación en el arte,

Es el medio a través del cual los jóvenes son capaces de crear y comunicar ideas complejas. El arte puede hacer visibles los problemas culturales, vividos y efimeros ya que se comunica a través de imágenes, sentimientos, colores y texturas. (Hickey- Moody, 2017, p. 1)

En ese punto, de acuerdo a Sánchez Aranegui (2018), se trata de confiar en sus capacidades, de generar espacios de producción y debate con el único objetivo de “(...) permitirles que sean ellos mismos” (p. 524). Ello, importa porque las personas con discapacidad y, en este caso, estudiantes con discapacidad intelectual que viven en contexto de pobreza urbana continúan siendo el colectivo históricamente olvidado, oprimido y excluido (Brogna, 2019). A partir de esto, diversas investigaciones refieren que los procesos de opresión que se ejercen sobre las personas con discapacidad, las desacreditan (Ferrante, 2020; Venturiello, 2016), produciendo un tipo de subjetividad acorde a estructuras capacitistas (Mc Ruer, 2020). A la vez, son destinatarias de políticas de compensación y de discriminación positiva (Apablaza, 2018), que las excluye de cualquier tipo de debate en torno a su reconocimiento (Butler, 2010; Fraser y Honneth, 2006), como sujetos políticos capaces de incidir en su propia cotidianeidad y existencia. A partir de estos debates el colectivo de estudiantes con discapacidad intelectual se configura así, como "lo abyecto de lo abyecto" (Schwamberger y Grinberg, 2020, p. 5).

Esto nos lleva a reflexionar sobre aquello que Barnes (2008) y Oliver (1990) plantearon cuando se investiga sobre discapacidad. Ambos autores proponen, que resulta fundamental la existencia de investigaciones en el marco de la discapacidad y, que recuperar las voces que están y estuvieron silenciadas se transforma en una necesidad y en un acto de enunciación política para visibilizar las injusticias que atraviesa el colectivo. En ese sentido Barnes (2008), sugería que "no hay un remanso de independencia o un punto medio cuando se investiga la opresión: los académicos e investigadores solamente pueden estar del lado de los opresores o de los oprimidos” (p.110).

Desde esta perspectiva entonces, ¿cómo determinar lo que puede un cuerpo?, ¿sus límites, fronteras y capacidades? ¿Cómo determinar lo que un sujeto puede desplegar en sus potencias y en sus debilidades? Creemos que la investigación educativa a través del arte puede utilizar estas perspectivas teóricas para mapear grupos afectivos y pensar nuevas capacidades para afectar y verse afectado (Youdell, 2006; Watkins, 2011). Lo anterior es vital, porque deviene en un investigar junto a otros y con otros en que el rol del 
investigador se corre de su posicionamiento "tradicional" y se vincula directamente con aquello que se produce en el acto investigativo. Este transitar la investigación mediante técnicas audiovisuales permite, "una visualización en tiempo presente de un material producido en otro momento y lugar que le da una densidad no equiparable a ningún otro formato, soporte y producto" (Heras Monner Sans y Miano, 2012, p. 36)

En este caso, quienes investigan mediante técnicas de participación se vuelve clave no sólo en el modo de "producir" conocimiento respecto del "fenómeno" a estudiar, sino, que se constituye como una propuesta de colaboración potente en el que, mediante el formato de taller, investigadores, jóvenes y docentes discuten, colaboran, recrean, piensan y debaten juntos. Este modo de indagación "ha permitido la aparición de valiosos aportes en áreas en las que la imagen cumple un papel central en el análisis, ya no solamente como fuente secundaria informativa e ilustrativa, sino como hecho social y como fenómeno cultural” (Cabrera y Guarín, 2012, p.9). No sin ello mencionar, que la trayectoria del uso de imágenes en las ciencias sociales creció al calor de diversas críticas. Al respecto, Sarah Pink puntualiza estas cuestiones en Doing Visual Ethnography (2009) y sostiene que "la clave para una [investigación] exitosa es la comprensión de las relaciones sociales y las agendas subjetivas a través de las cuales se producen y los discursos a través de los cuales adquieren significado" (p. 76), que como proponemos en este trabajo, lo hacen a través de la producción audiovisual.

En una misma línea Thompson (2008) sostiene que hacer investigación junto a los jóvenes, mediante técnicas visuales y artísticas, proporciona un campo fructífero en la que los sujetos, con los que se investiga, se vuelven protagonistas de la escena y siempre tienen algo para transmitir. Es decir, se convierten en "investigadores y expertos" del mundo que los rodea. Esta propuesta permite "revelar" en términos fotográficos, poner luz, a las historias silenciadas en las narraciones que toman cuerpo y forma mediante la producción y elaboración del pensamiento a través de las imágenes. Son esos modos que demandan a quien investiga, en campos complejos y sumamente precarios, pensar modos otros de acercarse a la realidad que se decide investigar. Modos que no sólo recuperan aquello que se dice, se ve o se observa en el campo de investigación. Son modos que como menciona Hickey-Moody (2012), se vuelva una práctica en sí misma y en la que la jerarquización de los sujetos se diluye.

\section{Método}

El enfoque metodológico se centra en una propuesta de investigación cualitativa de base múltiple (De Seena, 2015; Scribano, 2008;) que recupera distintos modos de recolección de la información a través de los aportes etnográficos (Guber, 2001), la observación participante y la técnica de producción audiovisual, que se materializa en cada uno de los encuentros entre estudiantes-docentes e investigadores. Ello, atendiendo a las estrategias que habilita la experiencia del trabajo artístico en las instituciones educativas emplazadas en contexto de pobreza urbana de gestión pública. Esta propuesta de indagación se propone como un taller de producción audiovisual, mediante un trabajo articulado y participativo (Langer et al., 2015; Schwamberger et al., 2020), entre el equipo de la universidad y una escuela de educación especial, que procura ser un espacio de construcción colectiva, con el objeto de generar instancias de reflexión y debate en torno a las experiencias de escolarización en contextos de fragmentación urbana y pobreza estructural.

Este modo de indagar y acercarse al campo (Guber, 2001), adquiere notoriedad y especificidad a partir de la articulación que se produce, por un lado, entre instituciones de diversa índole, como la universidad y la escuela especial, pero, en particular, por la presencia y reflexividad que requiere por parte del equipo de investigación. Ocurre tanto en el proceso de indagación como en el proceso de elaboración de la producción audiovisual que se discute en este trabajo. Este tipo de intervención procura no ser un espacio en donde operan jerarquías sino, justamente, se constituye en un escenario de colaboración, reflexión conjunta y a partir de allí, se expresan y se producen distintas experiencias que resultan transformadoras, tanto para los jóvenes que participan de la propuesta del taller como para quienes deciden investigar. En efecto, transitar la investigación de este modo en el que se es partícipe de la propuesta y, a la vez, un nexo para acompañar a los jóvenes a incluirse en el taller audiovisual, trastoca los modos hegemónicos en que se piensa y se hace investigación. 
El trabajo de campo se realiza en una escuela de educación especial emplazada en contexto de pobreza urbana de una localidad de la provincia de Buenos Aires, de Argentina. Allí asisten a diario casi quinientos estudiantes con discapacidad intelectual, entre 6 y 25 años, que habitan los espacios más empobrecidos de la localidad. La escuela se emplaza, en la región noroeste, donde se asienta el mayor porcentaje de barrios denominados villas miseria y asentamientos. Estos, surgieron al calor de los procesos de industrialización y los habitantes, encontraron en las zonas próximas al Río Reconquista, un espacio para asentarse y ocupar territorios. Debido a la cercanía con los afluentes del río y los basurales a cielo abierto próximos a los hogares (Besana et al., 2015), afecta de modo particular la vida de quienes allí habitan. Por lo tanto, entendemos al territorio como producción social en una trama simbólica y material, de relaciones de fuerza y espacio de lucha (Arfuch, 2006; Grinberg, 2009, 2020). Así, el territorio se produce a través de la intervención de los sujetos sobre este, pero, también produce sentidos que, junto con las instituciones que lo conforman, modela las maneras en que asumen distintas posiciones en el mundo, las que fuera de toda neutralidad, definen a través de la biopolítica el destino de la población (Foucault, 2007).

El trabajo de campo se realiza, desde el año 2016, en el marco de un taller de producción audiovisual, mediante una asistencia semanal, junto a un grupo de estudiantes -varones y mujeres- entre 15 y 17 años, en el que se acompaña a docentes a cargo de uno de los talleres de formación integral que la escuela posee. Esta propuesta de asistencia sostenida en el tiempo, creemos, es lo que permite a quien investiga convertirse, devenir en un actor más de la institución en el que se producen lazos de confianza, acompañamiento y trabajo mutuo. Esto lleva a tener presente una firme reflexividad, pero, a la vez, una constante satisfacción del trabajo que se realiza. Ello, a partir de pensar la investigación de manera articulada, en el que sólo es posible, mediante la construcción y promoción de parejas pedagógicas con el objetivo de acompañar a las docentes del grupo escolar en todas las actividades que se propongan. Este acompañamiento reviste no sólo a los fines de la indagación, sino, que, a través de los lazos establecidos, el equipo de investigación se sumerge en todas o la gran mayoría de actividades que propone la institución escolar.

Asíla propuesta de producción audiovisual, se vuelve una herramienta mediadora y transformadora para que los jóvenes elaboren y pongan en acto mediante imágenes en movimiento, en este caso, su propia visión del mundo, a la vez, que les permite pensar(se) en el entramado complejo de la realidad que viven (Grinberg y Abálsamo, 2016). Una realidad de un presente devenido frágil, incierto, pero que siendo realizadores/productores audiovisuales narran sus posicionamientos, los lugares que habitan, sus sensaciones, sus proyectos, sus miedos. En efecto, se sumergen en sus vidas a través de sus propios relatos, que no son relatos individuales, sino que son siempre con otros y junto a otros. Como establecen Cabrera y Guarín (2012), "el uso de imágenes generadas por los propios sujetos, o bien aquellas que resultan de la coproducción de conocimiento por parte del investigador y los sujetos"(p. 17), deviene en una propuesta metodológica que contribuye no sólo a producir información a través de ella, sino, como herramienta vital para el proceso de "construcción teórica resultante de la interacción entre la orientación epistemológica del investigador, el contexto de grabación y el instrumento de registro" (Cabrera y Guarín, 2012, p. 18).

Es por ello que las técnicas de recolección de información resultan de un registro múltiple. Por un lado, a través de la observación participante se recupera mediante notas de campo todo lo que ocurre en cada uno de los encuentros organizados semanalmente en el taller. La organización del taller se elabora junto a la docente a cargo que debe seguir el currículo establecido para su grupo escolar. En segundo lugar, los talleres audiovisuales se filman mediante un registro de doble mirada: una de ellas, a través del lente de los estudiantes que toman la cámara y filman lo que acontece en el taller y, del mismo modo, el equipo de investigación dispone una cámara fija que registra desde una perspectiva no invasiva todo lo que allí ocurre. Esto permite ver una y otra vez lo ocurrido en cada encuentro y se complementa con las notas de campo a partir de la observación participante realizada (Langer et al., 2015). Finalmente, la tercera fuente de recolección de información, que da sustento a este artículo, se refiere a la producción audiovisual resultado de todo un año de trabajo junto a los jóvenes y docentes. Entre esta triada de registros, notas de campo, registro audiovisual y la producción final resultan las técnicas que dan cuerpo al trabajo de investigación conjunta producido entre la universidad y la escuela especial.

En esta dirección, en cada encuentro se despliegan distintas actividades y registros audiovisuales vinculados con las temáticas propuestas y seleccionadas por el grupo de estudiantes. En este caso, a partir de los intereses del grupo escolar, se realiza una investigación exhaustiva sobre la contaminación ambiental que ocurre en los barrios que habitan. Para ello, se ubican y registran actores claves para entrevistar y pro- 
fundizar la investigación. El grupo escolar decide entrevistar a un docente de la universidad especialista en cuestiones ambientales de la localidad en la que se emplaza la escuela y la universidad. Paralelamente, se construye un guion/escaleta de la historia que desean contar, en el corto audiovisual, que pueda dar cuenta, mediante el recorte y el montaje que ellos realizan, de una realidad que los atraviesa, no sólo, en los barrios, sino, en sus escuelas y en sus vidas. Creemos junto con Heras Monner Sans y Miano (2012), que "el lenguaje audiovisual se convierte en una herramienta privilegiada para el registro y análisis de la interacción social ya que permite cubrir todos estos niveles que se ponen en juego en la comunicación humana" (p. 23).

El análisis del material de campo se realiza a través del método comparativo constante (Glaser y Strauss, 1967), constituido por el corpus de registros fílmicos de cada encuentro semanal del taller, anotaciones del diario de campo del grupo de investigación y el corto audiovisual "Ciudad Fantasma". Para el procesamiento de la información se recurrió al uso del Software de Análisis Cualitativo ATLAS Ti versión 7.1. En este análisis procuramos el desarrollo de categorías conceptuales para lograr acercamos a la comprensión de las situaciones de vida, muchas veces silenciadas, atravesadas por el grupo de estudiantes en el taller. Este método permite, a través de la comparación de sucesos y eventos, generar distintas categorías, integrarlas a sus propiedades, compararlas hasta su saturación, delimitar su alcance y establecer categorías clave que den cuenta del proceso de indagación y reflexión que emanan a partir de ellas.

Es allí que, mediante la lectura de los registros y la visualización de la filmación, así como el trabajo final del corto, se logra codificar, en un primer momento de modo abierto y luego axial, en categorías analíticas mediante un proceso inductivo que se vuelve una instancia de creación y de trabajo conjunto que da origen a las categorías que desplegamos en el apartado de resultados. A partir de la codificación y el establecimiento de propiedades en cada una de las categorías, se establecieron dos grandes grupos que refieren, por un lado, a las formas en que cada joven enuncia-denuncia las injusticias que viven y el modo en que habitan los espacios urbanos. Titulamos a esas categorías de análisis "discursos de potencia" y "sobre la vida en los barrios".

Discursos de potencia comprende una variedad de códigos resultantes de los enunciados producidos por los propios jóvenes: "el olor de la basura”, "el agua es marrón”, "algo hay que hacer”, "dejen de contaminar", "somos el futuro", entre otros. Sobre la vida en los barrios las propiedades se establecen a partir de lo que los jóvenes nos dicen con sus videos, imágenes y frases: "el barrio se inunda", "llueve y ya sabés que no vas a la escuela", "la casa que me gustaría tener", "que no haya más basura en la calle" y "me gusta donde vivo". Los datos que se analizan en el apartado de resultados forman parte de la triada metodológica desarrollada, que ocurre entre las notas de campo, el registro audiovisual producido en los talleres por los estudiantes junto al equipo de investigación y, el corto final.

Importa aclarar que las decisiones que se toman respecto de la elaboración de la idea que da origen al corto audiovisual, la construcción de la historia, así como el montaje y la edición final se constituyen como parte de una dialógica entre los jóvenes, los docentes y los integrantes del equipo de investigación (Langer et al., 2015; Schwamberge et al., 2020). Todo lo que ocurre en el marco del taller de producción audiovisual, se elabora mediante la construcción conjunta y el acuerdo colectivo. Esto involucra desde la toma de decisión de qué decir y que no decir en el corto, qué estrategias utilizar para elaborar el cómo decirlo, mediante la selección de materiales con los que se trabajará, así como la elección de la historia, la música para cada una de las escenas y quiénes serán los informantes clave para la investigación en relación a la temática seleccionada que, en este caso, se vincula con la contaminación ambiental de los barrios que viven.

Estas decisiones se toman en un marco de reflexión y autorreflexión que ocurre en la propia práctica del taller. Es decir, ocurre en acto, mientras se desarrollan los encuentros y las actividades que se despliegan. Son estudiantes con discapacidad intelectual, los protagonistas de esta historia, que se preocupan y preguntan por situaciones traumáticas, como la contaminación ambiental, que los toca de cerca, los incomoda y no se quedan de brazos cruzados. Es justamente allí, donde toman la cámara y deciden poner rec y hablar sobre esos temas que como Grinberg y Abálsamo (2016) mencionan,

Contribuye no sólo a poner palabra a los silencios que gritan (Grinberg y Dafunchio, 2015), sino generar instancias para contrastar los modos en que los marcos de interpretación me- 
diáticos afectan los modos en que docentes y estudiantes pensamos y percibimos la vida del barrio y la escuela. (p. 10)

Una díada inseparable: barrio y escuela, escuela y barrio que se produce como un infinito de relaciones de fuerza y de resistencia (Deleuze, 1987; Foucault, 2013). Son las lógicas y dinámicas de la urbe que son parte también de lo que sucede en el interior de las instituciones que, mediante las voces y producciones audiovisuales de los jóvenes, toman voz propia. Poner rec, construir un guion, editar, montar, en definitiva, crear, se vuelve en estos espacios de la urbe y en esta escuela en particular un acto de grito que enuncia lo silenciado (Grinberg y Dafunchio, 2013). Sobre estas cuestiones discutimos en el apartado de resultados que revisten particular atención dado que se centran en discursos y enunciados que se alejan de las dicotomías y análisis binominales de las problemáticas que los aquejan.

\section{Resultados}

\subsection{Discursos de potencia: enunciación política ante la desigualdad}

La producción artística se constituye como una oportunidad para discutir temas actuales (Carpentieri et al., 2020), deconstruir enunciados estigmatizantes (Brogna, 2019; Ferrante, 2020) y se posiciona como un espacio en el que debatir temáticas cotidianas. Ciudad Fantasma, corto audiovisual tejido entre la vida de estudiantes con discapacidad, la pobreza y contaminación ambiental es una de las tantas historias silenciadas y que es necesario conocer. Para ello, el grupo escolar, luego de distintos debates, propuso la construcción de una historia, que pone en primer plano y evidencia la contaminación del zanjón- del Rio Reconquista- que circula por sus hogares y cómo ello afecta a sus vidas y barrios. Algunos de los debates iniciales giraron en torno a ello:

(...) en mi barrio no pasan a buscar la basura, queda toda tirada y la gente tira siempre todo ahí, en una misma esquina. Siempre hay un olor horrible. A veces pasa un camión y lo levanta y se lo lleva. No sé dónde lo tirarán. (Registro de Campo propio, junio, 2018)

A veces se ven montañas de basura, el olor es insoportable. Me meto en mi casa y cierro las ventanas. Pero se siente igual. (Registro de Campo propio, mayo 2018)

Esta problematización, permite a los jóvenes recrear múltiples escenarios y lecturas de una problemática que nos aqueja y nos compete a todos. Pero que no todos se involucran. No sólo ello, sino que este tipo de producciones, en el marco de la escuela y un proyecto de articulación, permite poner luz y hacer foco en las realidades que atraviesan. Sobre la contaminación una de las jóvenes comenta:

A veces el agua viene de un color raro. Nosotros tenemos agua por un caño negro de plástico que llega del vecino. A veces mi papá lo tiene que estar arreglando por que se pincha y se empieza a inundar todo el patio. (Registro de Campo propio, mayo 2018)

A partir de la primera instancia de debate respecto de lo que ocurre en los barrios que habitan, los jóvenes deciden elaborar una historia de ficción que dé cuenta de cómo toda la población de un barrio, subsumido en la contaminación ambiental, abandona su lugar de residencia, a causa de ella, como forma de denuncia de lo que allí acontece. Para ello, deciden buscar información y entrevistar a un especialista en la temática. La entrevista, se logra desplegar en el espacio de la universidad en el que los jóvenes acceden por primera vez a esta institución. La misma, se desarrolla en el espacio de trabajo del docente investigador y se constituye en un instrumento de diez preguntas elaboradas por los jóvenes. Una de las preguntas, que seleccionan también para incorporar en el corto final, se vincula con su preocupación por el tema:

Roby [estudiante varón]: ¿cómo estudiantes que podemos hacer para que esto [la contaminación] ocurra cada vez menos?

Entrevistado: Tratar de informarse y de pensar un problema que es general donde uno pueda hacer algo a nivel individual pero que en realidad los grandes culpables no son ni los vecinos, los grandes culpables por lo general son los gobiernos, las instituciones que tienen una responsabilidad para con eso y para mantener la salud de todos nosotros y, las empresas. 
(Extracto de Entrevista realizada por los jóvenes al investigador especialista en contaminación ambiental, septiembre de 2018)

Una vez, finalizada la elaboración de la historia y el guión que graficamos en la siguiente imagen de la escaleta, en los subsiguientes encuentros, se realizó el proceso de maquetación de cada una de las escenas. El grupo de jóvenes optó por la realización de una producción audiovisual que combina distintas herramientas cinematográficas. Esta producción se nutre de filmaciones propias, del grupo de estudiantes, de los espacios urbanos, fotografías, la entrevista en profundidad a los referentes investigadores sobre la contaminación ambiental y la utilización de la técnica del stop-motion. En la siguiente imagen recuperamos la escaleta producida para las escenas y alguna de las tomas de las maquetas para crear el efecto de stop-motion:

\section{Figura 3}

Imagen izquierda: Escaleta del guión Ciudad Fantasma. Imagen derecha producción de maquetas por parte del grupo escolar para el stop-motion
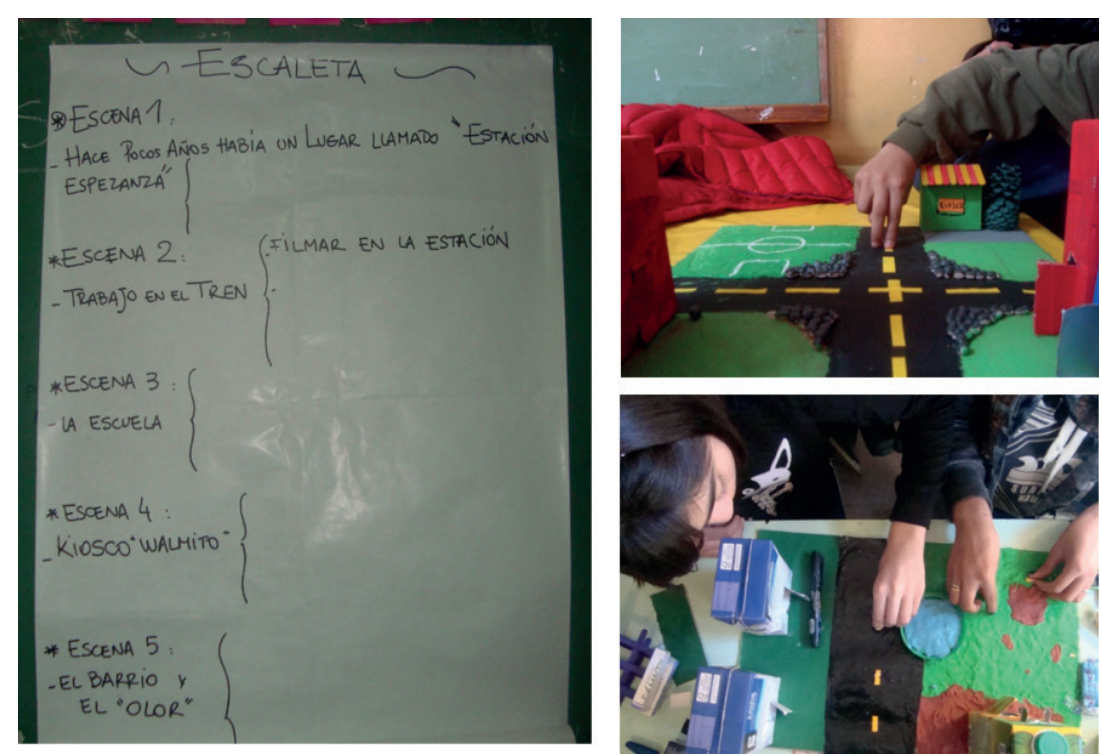

La realización de la escaleta estuvo acompañada de debates respecto de cuáles serían los mejores recursos audiovisuales para utilizar en cada una de las escenas a construir. Recuperamos una conversación producida a partir de la primera:

Docente: La historia empieza contando que había un lugar llamado "Estación Esperanza" que por ahí pasaba un tren. ¿Qué imágenes, videos ofotos pueden ir en esta parte de la historia?

Axel [estudiante varón]: algún video de la estación de tren.

Equipo de investigación: ¿Dónde lo podemos filmar eso?

Axel: Puedo ir después de la escuela y filmar cuando me bajo del tren.

Roby: ¿Y si buscamos por internet?

Axel: Mejor que sea nuestro, es más lindo.

Selva: Si, mejor. Filmá vos Axel. (Registro de campo propio, mayo de 2018)

Aquí el grupo escolar produce, construye, crea espacios para mostrar sus vidas. Utilizan materiales que serán descartados en el basural que registran en el video, material que vuelven a utilizar y producen magníficas escenas. En esas imágenes encontramos producción de vida, de colores, de texturas, con "una producción que no es más que una afirmación irreductible a la unidad por lo que, más que expresar carencias que requieren ser completadas, producen lo real” (Grinberg, 2012, p. 83). 
Eso real que produce el grupo, que realizan videos de sus barrios o diseñan maquetas con materiales reciclables, son esas imágenes insoportables, que incomodan y que despuntan (Barthes, 2003). Empero, es allí, donde el grupo estudiantil propone enunciados de resistencia. Recuperamos para ello, las frases construidas y utilizadas para dar cierre al corto audiovisual que surgen en uno de los encuentros del taller:

Docente: que proponemos para el cierre del corto.

Selva [estudiante mujer]: ¿alguna música de terror?

Toby [estudiante varón]: no eso no, algo más lindo. Pero, ¿qué puede ser?

Integrante equipo: ¿Se animan a grabar unos mensajes?

Luca [estudiante varón]: $\mathrm{mmm}$, no a mí me da vergüenza

Docente: $y$ que se te ocurre para que no te de vergüenza

Luca: ¿podemos escribir los mensajes?

Selva: ¡Sí!, eso es mejor.

Docente: Pensemos entre todos que podemos poner en unos carteles, ¿les parece? [Todos los jóvenes contestan al unísono que sí]. (Registro de campo, octubre de 2018)

En las imágenes que siguen, se materializan las ideas concertadas. Observamos tres estudiantes, uno de ellos sostiene un cartel de color azul que contiene el siguiente mensaje: si reciclás, reducís basura, escrito de su puño y letra. Arriba a la derecha otro de los estudiantes escribe sobre un cartel de color rosa, paren de contaminaros y finalmente una estudiante con una hoja de color verde escribe y muestra la frase: somos el futuro, para quienes tengan la oportunidad de visualizar el corto:

\section{Figura 4}

Mensaje del grupo de estudiantes ante la contaminación: \#Si reciclás, reducís basura. \#Paren de contaminarnos. \#Somos el futuro

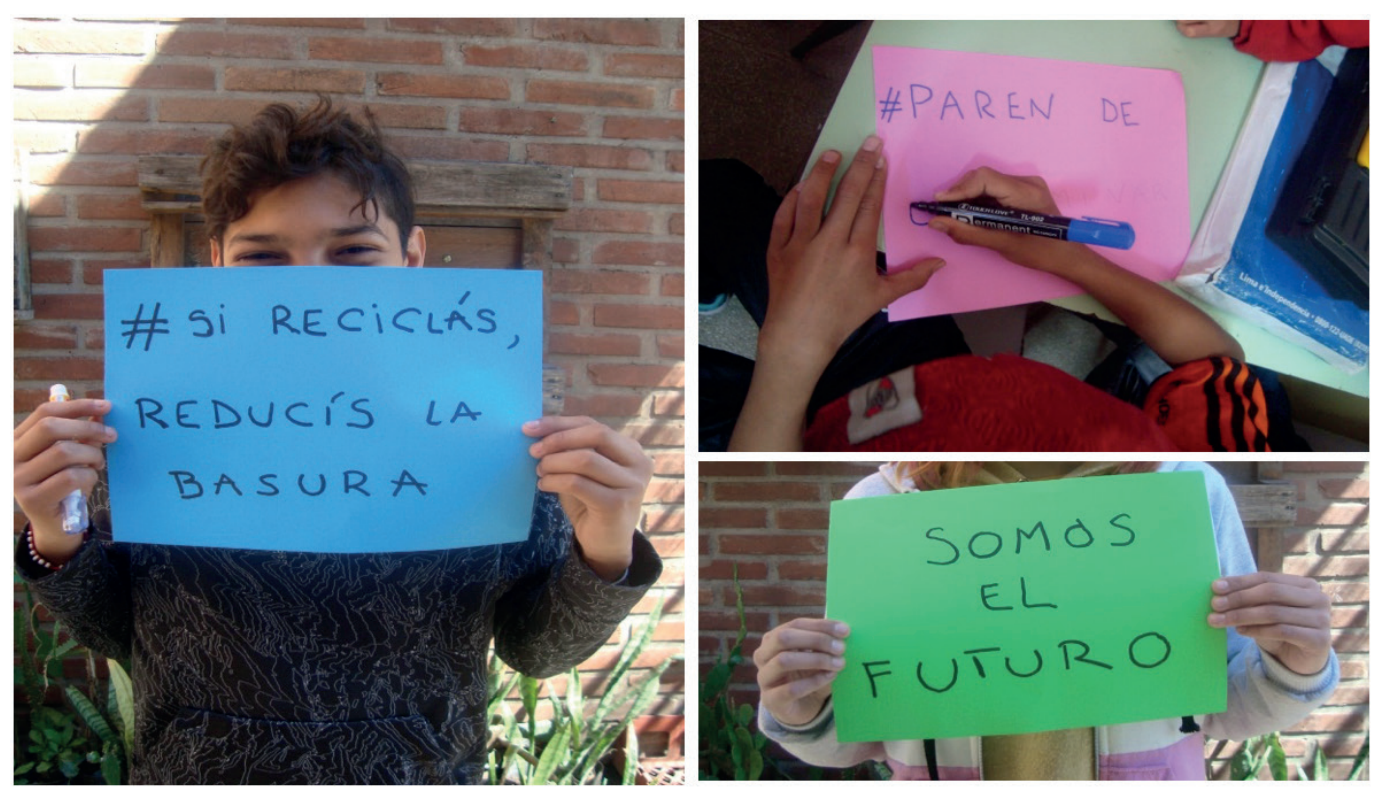

En esa denuncia y enunciación política, está también la música elegida para retratar como esta Ciudad se vuelve fantasmática, porque sus habitantes, ante la elevada contaminación de una fábrica, deciden abandonar el lugar. Es allí donde la "Infinita Tristeza" invade, acordes de la canción que suena al final, mientras la ciudad se abandona. Sin embargo, mediante sus ideas proponen seguir creyendo que a pesar de las condiciones que el Estado arroja a los habitantes de los barrios más pobres, ellos son el futuro. 


\subsection{Sobre la vida en los barrios: ¿Una ciudad fantasma?}

La producción audiovisual procura "el posicionamiento del sujeto en el mundo, en la historia" (Grinberg y Abalsamo, 2016, p. 4), y es el grupo de estudiantes quienes toman la cámara y muestran la vida en sus barrios. Para ello, recuperamos el registro de campo sobre la visualización de uno de los videos producidos por uno de los estudiantes en el marco del corto "Ciudad Fantasma":

Filma con su celular caminando hacia la esquina, la imagen se mueve, pero ya se ve la ochava de bote a bote tapada de agua. La vereda llena de residuos tirados y arboles cortados por la mitad. Se apura, camina más rápido y se para en la esquina, hay un montículo de escombros y espera, hace un paneo de $180^{\circ}$ hay barro en la vereda y está toda la esquina y las calles inundadas. Se acerca un colectivo, el 237 que sale de la terminal de Lanzone, vacío sin gente, lo filma en todo su recorrido, ya que mientras se traslada el colectivo levanta fuertemente el agua que está ahí depositada, el ruido que se escucha de la imagen es muy fuerte ya que levanta bastante agua. Luego realiza una toma de la estela y el recorrido del agua que va dejando el colectivo. Se ven claramente las olas que generan en la calle llegando hasta la vereda y tapándola. Vuelve a hacer un paneo de toda la parte inundada y luego pasa un camión grande y le toca bocina, también filma su recorrido y como levanta el agua hacia los costados, esta vez el caudal es mayor por la velocidad en la que va el vehículo. Esto ocasiona que llegue más cantidad de agua a las veredas y por ende a las casas. Durante la filmación de este video el estudiante no emite ninguna palabra, ni ningún sonido, las imágenes hablan por sí solas. (Registro de Campo propio, mayo 2018)

El estudiante se queda callado, solo menciona que quería salir a filmar por la noche cuando llovía torrencialmente, pero eso no era posible, porque no dejaba de entrar agua a su casa. Sin embargo, espera hasta la mañana siguiente y sale a registrar aquello que acontece. En la imagen que sigue [Figura 1] se observa una captura de pantalla del video que él ha producido y se ha utilizado en el corto audiovisual:

Figura 1

"Yo vivo en Lazone"

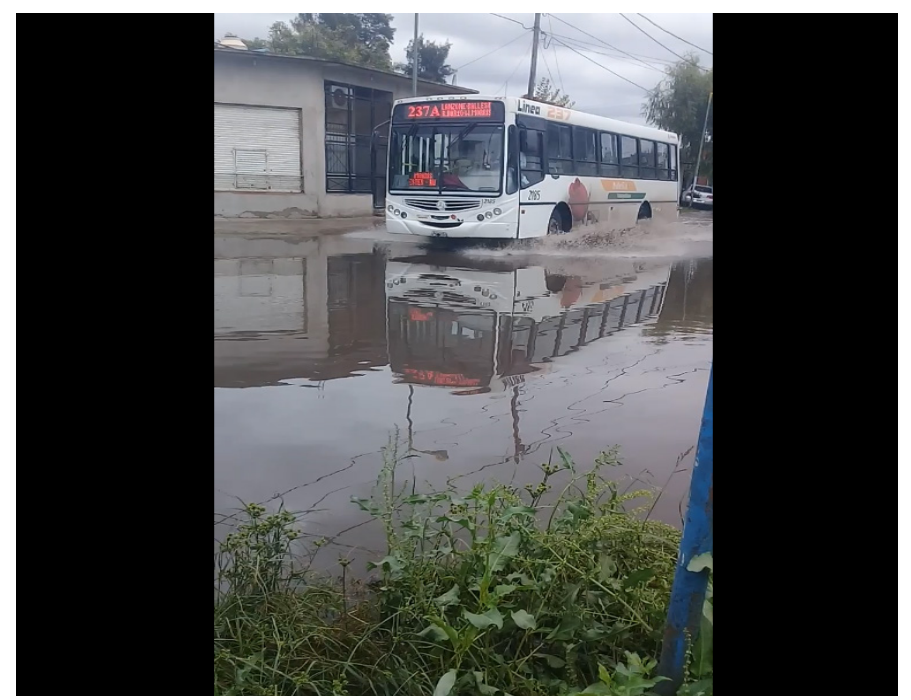

Nota. Elaborado por uno de los estudiantes que asiste al taller

En este registro que se desprende del video observado entendemos que hay una ligazón entre esas intersecciones que se trazan entre la escuela y el barrio (Grinberg, 2012), intersecciones que no suponen una correspondencia y reproducción lineal entre los hechos que suceden, sino, a través de la palabra de los estudiantes se pone en discusión esos acontecimientos, a través de sus producciones. Al respecto recuperamos un breve fragmento de la puesta en común luego de haber visualizado el video casero que trajo el estudiante:

Axel: empezó a llover y sabía que se iba a inundar rápido la calle. Pero no podía salir con el celular a grabar. Por eso filmé desde la ventana. A la mañana cuando me levanté quise ir a 
tomar el colectivo para venir a la escuela y estaba todo inundado. Agarré el celular y filmé justo cuando pasaba el colectivo.

Selva: ¿Te toca bocina el colectivo porque te conoce?

Axel: Si como salgo a la misma hora siempre me toca el mismo colectivo.

Roby: ¿El agua entra a tu casa?

Axel: A veces si, a veces no. A veces cae por el techo en un lugar de la cocina. A veces como ayer, entra directo porque se inundan las calles y no podemos salir. (Registro de campo propio, mayo de 2018)

Son jóvenes que, se manifiestan mediante enunciados a través de un accionar, como en este caso, de situaciones de vida dónde la palabra enmudece porque allí no es posible decir nada más. Solo resta observar las imágenes, como las grabadas por este estudiante, y analizar aquello que se produce en esa conjunción inalterable e indisociable entre palabra e imagen dicha y producida por ellos mismos, cómo las muestran, el modo en que lo hacen y dónde deciden hacen zoom como en filmar todo un recorrido de estela de agua, para narrar sus vidas.

En este sentido, centramos la reflexión "en la vida cotidiana de los jóvenes a través de su mirada, pensamientos, deseos y percepciones (...) de sus formas, de sus modos autorizados de hacer y decir" (Grinberg, 2012, p. 81). Como lo hace también una de las jóvenes que decide registrar su barrio mediante un dibujo de la casa que le gustaría tener:

Figura 2

La casa que me gustaría tener

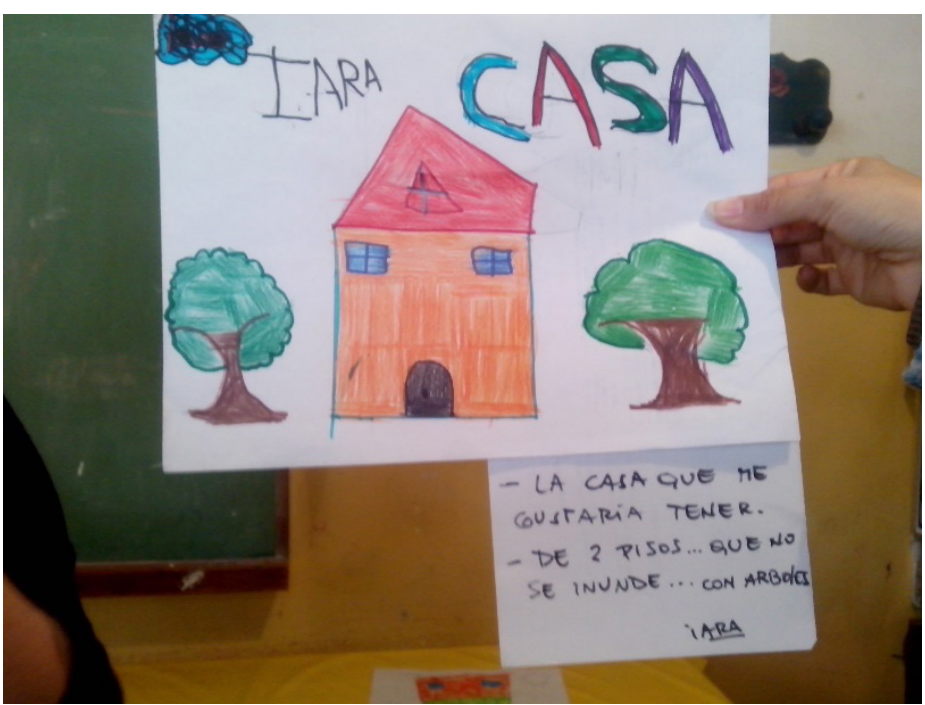

Nota. Dibujo de una estudiante

En este dibujo que se desprende de una de las primeras actividades diagramadas y propuestas junto a las docentes para lograr acercarnos a la vida en sus barrios, esta joven decide plasmar su idea a través de un diseño gráfico de una casa de dos plantas, con paredes de color naranja y el techo de color rojo, que se encuentra rodeada por dos árboles frondosos. Una vez finalizada esta actividad, se realiza una puesta en común de lo que cada uno ha producido a través de sus propias elaboraciones. Se conversa con la joven sobre lo que se encuentra allí plasmado. La estudiante responde mediante frases cortas sobre su composición, asignando una palabra única a cada elemento graficado. Debajo del dibujo se observa un cartel, con lo que menciona, escrito en letra imprenta por su docente. El mensaje es claro y contundente. Es la casa que le gustaría tener, de dos pisos y con árboles. Pero sitúa en particular el deseo de que no se inunde. Expresar una situación de vulneración de derechos por medio de un dibujo, es lo que vuelve al arte un ámbito de potencia en las vidas de estos jóvenes. 


\section{Conclusiones}

En las páginas anteriores procuramos a modo de lienzo, como un study board, trazar algunas líneas que, a partir del trabajo colaborativo con una escuela de educación especial emplazada en contexto de pobreza urbana de la provincia de Buenos Aires, permite adentrarnos a los modos en que los jóvenes, viven, piensan y sienten sus barrios así, como las condiciones de desigualdad que transitan. En particular, hicimos foco en la elaboración conjunta con docentes y estudiantes sobre la experiencia de un corto audiovisual titulado Ciudad Fantasma, que recupera debates construidos por el grupo escolar sobre la contaminación y degradación ambiental.

Mediante la producción audiovisual se procuró dar cuenta de las continuidades, discontinuidades y tensiones que atraviesan la vida de estos jóvenes, atendiendo también al lugar que ocupa la escuela para que estos procesos, en efecto, se produzcan. Entre esas tensiones los jóvenes muestran una realidad silenciada o mal comunicada en los medios de comunicación. Así de acuerdo a Carpentieri y otros (2020),

\section{Las imágenes se vuelven recurso con un significativo poder de interlocución e interpelación en su simpleza. No se trata del amarillismo mediático ni de la compasión o romantización de esos otros (Grinberg, 2010) sino de la cotidianeidad de la vida que es vivida desde esos yo. Esos siempre otros. (p. 20)}

Son enunciados que como observamos en el guion de la historia que presentan, producen la idea de abandonar la ciudad debido a la extrema contaminación, pero que, a pesar de estas condiciones, los jóvenes, logran interpelar cualquier política y a partir de allí denunciar lo que ocurre en sus barrios. Su yo en el mundo importa. Ellos lo demuestran, porque son el futuro, y saben cómo intervenir en sus barrios y en sus vidas. Es preciso prestar particular atención entonces, a aquello que muchas veces es silenciado o no escuchado y, como en este caso, deviene imagen y sonido que, mediante la realización de este corto, otros observan y escuchan. Los jóvenes, en primera persona, toman su celular y graban una calle inundada por completo, a la vez, que dibujan una casa de dos plantas para no estar expuestos al agua que rebalsa cada vez que llueve. A partir de estas producciones afirman su identidad en el mundo, frente a sí mismos y frente a los otros.

Mediante estos registros se accedió a los micros detalles de una cotidianeidad traumática de la vida, como hemos propuesto, son la contracara del miedo abyecto (Grinberg, 2012) que sopesa en estos barrios, pero que aquí no tiene lugar. Ese lado b de la historia que transcurre en estos espacios de la urbe no sólo confirma la (im)posibilidad sino, que es expresada por la producción deseante de los jóvenes, que, en situaciones extremas, como la inundación y la contaminación ambiental, este grupo escolar los invierte y logra producir enunciados de afirmación de la vida y de resistencia. Allí donde se espera la muerte, la enfermedad, el desamparo, estos jóvenes demuestran la vida. Entre sus múltiples matices, entre sus múltiples desigualdades, pero que mediante estos recursos nos devuelven una mirada otra de lo que ocurre. A través de las imágenes, expresan y afirman los que les preocupa e interesa.

Se trata, entonces, de ubicar la circulación de la palabra en sus múltiples lenguajes, mediante la educación artística, que en este caso toma forma como producción audiovisual y se inserta en la forma particular que los jóvenes consiguen producir distintas instancias de pensamiento y discurso que rompe con las imágenes de abyección que atraviesan a las escuelas emplazadas en estos territorios y a los barrios que habitan: "se trata de producir, espacios de palabra que puedan poner en cuestión los marcos mediático y políticos de interpretación de la vida (Butler, 2010) procurando desafiar las narrativas dominantes sobre la ciudad" (Grinberg y Abálsamo, 2016, p. 5).

Así la práctica artística y la educación en el arte como potencia, se sitúa como experiencia significativa en el ámbito escolar, pero a la vez, como posible intervención ante las desigualdades, que permite construir espacios -sociales y escolares- más justos menos estigmatizantes y más vivibles. Aquello que debiera ser la no producción de ciudades fantasma, como una acción gubernamental, son los jóvenes quienes toman la lente y denuncian mediante prácticas en el arte modos para la construcción de una sociedad con justicia social. Las distintas técnicas que permite la producción artística a través de la educación en y por el arte para abordar el conocimiento, en este caso, sobre la situación ambiental y de la vida en los barrios que transitan los jóvenes, "nos brinda el marco para pensar cómo la cultura y los hábitos de pensamiento 
pueden hacer visible algunas cosas y hacer a otras más fácil de ignorar o incluso no verlas nunca" (Hickey-Moody y Proasi, 2021, p. 4).

En las prácticas artísticas y audiovisuales encontramos ese plus que, en la mediatización y banalización de las imágenes instantáneas, muchas veces, no suele ocurrir. "No somos nosotros los que hacemos cine, es el mundo que se nos aparece como un film” (Deleuze, 1987, p. 227). El mundo está allí, y son los jóvenes quienes intervienen en el lienzo de la vida, montan imágenes, recortan figuras, construyen maquetas y van transformando su pensamiento en el mismo momento que se vuelve acto (Schwamberger et al., 2020). Aquí, el mostrar el mundo, que punza y afecta, obedece a otra cuestión que como nos menciona Larrosa (2006), ante esta experiencia se sale/salimos transformados. La educación mediante estas prácticas conmueve y moviliza de modo tal, que si bien, quedamos perplejos, seguramente algo se ha trastocado.

Para finalizar, nos interrogamos a partir de estas propuestas de intervención en el arte para trazar futuras líneas de indagación sobre la producción de subjetividades desde la perspectiva de los nuevos materialismos (Hickey-Moody y Page, 2015), en que se despliegan estos procesos de producción artística en contextos marcados por una elevada precariedad y pobreza estructural. Creemos que allí está la clave para pensar mundos más justos.

\section{Agradecimientos}

Este trabajo de investigación fue posible y se sustenta a partir de la Beca Doctoral 2016-2021 en Temas Estratégicos del Consejo Nacional de Investigaciones Científicas y Técnicas (CONICET).

\section{Referencias}

Apablaza, M. (2018). Inclusión escolar, marginación y apartheid ocupacional: Análisis de las políticas educativas Chilenas. Journal of Occupational Science, 25(4), 1-13. https://doi.org/10.1080/14427591.2018.1487260

Arfuch, L. (2006). Las subjetividades en la era de la imagen: De la responsabilidad de la mirada. En I. Dussel y D. Gutiérrez (Comps), Educar la mirada: Políticas y pedagogías de la imagen (pp.16-35). Manantial.

Barnes, C. (2008). Las teorías de la discapacidad y los orígenes de la opresión de las personas discapacitadas en la sociedad occidental. En L. Barton (Ed.), Discapacidady Sociedad (pp. 19-33). Morata.

Barthes, R. (2003). La cámara lúcida. Notas sobre la fotografía. Paidós.

Besana, P., Grinberg, S. y Gutiérrez, R. (2015). Pobreza urbana, comunidad local y estado-socio en Argentina: La provisión de servicios públicos en un asentamiento de la región metropolitana de Buenos Aires. Revista Mexicana de Ciencias Políticas y Sociales, 60(225), 79-102. https://doi.org/10.1016/S0185-1918(15)30020-9

Brogna, P. (2019). El campo académico de la discapacidad: Pujas por el nodo de sentido. Acta Sociológica, 80, 25-48. https://doi.org/10.22201/fcpys.24484938e.2019.80.76355

Butler, J. (2010). Cuerpos que importan. Sobre los límites materiales y discursivos del sexo. Paidós.

Cabrera, M. y Guarín, O. (2012). Presentación. Imagen y ciencias sociales: trayectorias de una relación. Memoria y Sociedad, 16(33), 7-22.

Carpentieri, Y., Grinberg, S. y Armella, J. (2020). Los unos y los otros: Vidas comunes en tiempos digitales. Cuestión, 2(66), e486. https://doi.org/10.24215/16696581e486

Deleuze, G. (1987). La imagen-tiempo: Estudios sobre cine 2. Paidós.

De Seena, A. (2015). Caminos cualitativos: Aportes para la investigación en ciencias sociales. CICCUS.

Didi-Huberman, G. (2008). Cuando las imágenes toman posición. El ojo de la historia. Antonio Machado.

Dussel, I. (2006). Educar la mirada. Políticas y pedagogía de la imagen. Manantial. 
Ferrante, C. (2020). La “discapacidad” como estigma: Una mirada social deshumanizante. Una lectura de su incorporación temprana en los disability studies y su vigencia actual para América Latina. Revista Pasajes, 10, 11-26.

Foucault, M. (2007). Nacimiento de la biopolítica. Siglo XXI.

Foucault, M. (2013). La arqueología del saber. Siglo XXI.

Fraser, N. y Honneth, A. (2006). ¿Redistribución o reconocimiento? Morata

Glaser, B. y Strauss, A. (1967). El descubrimiento de la teoría de base. Chicago Aldino Publishing.

Grinberg, S. (2009). Políticas y territorios de escolarización en contextos de extrema pobreza urbana. Dispositivos pedagógicos entre el gerenciamiento y la abyección. Archivos de Ciencias de la Educación, 10(3), 81-98.

Grinberg, S. (2012). Escuela, producción audiovisual y subjetivación en contextos de extrema pobreza urbana. Polifonías Revista de Educación, 1(1), 75-94.

Grinberg, S. (2020). Etnografía, biopolítica y colonialidad. Genealogías de la precariedad urbana en la Región Metropolitana de Buenos Aires. Tabula Rasa, 34, 19-39. https://doi.org/10.25058/20112742.n34.02

Grinberg, S. y Abalsamo, M. (2016). La escuela como espacio de lo común. Circulación y producción de la palabra en escuelas emplazadas en contextos de extrema pobreza urbana. CLACSO.

Grinberg, S. y Armella, J. (2021). Cartografías de la mirada otra: Jóvenes, pobreza urbana y producción audiovisual en la era postmedia. Praxis Educativa, 25(1), 1-18. https://doi.org/10.19137/praxiseducativa-2021-250106

Grinberg, S. y Dafunchio, S. (2013). Biopolítica y experiencia de escolarización en contexto de extrema pobreza urbana y degradación ambiental. Magistro, 7, 246- 269.

Guber, R. (2001). La etnografía. Siglo XXI.

Heras Monner Sans, A. I y Miano, M. A. (2012). El lenguaje audiovisual en la investigación social y la comunicación pública del conocimiento. Ciencia, Público y Sociedad, 1, 18-40.

Hickey-Moody, A. C. (2012). Youth, arts and education. Routledge. https://doi.org/10.4324/9780203855829

Hickey-Moody, A. C. (2017). Arts practice as method, urban spaces and intraactive faiths. International Journal of Inclusive Education, 21(11), 1083-1096. https://doi.org/10.1080/13603116.2017.1350317

Hickey-Moody, A. C. y Page, T. (2015). Arte, pedagogía y resistencia cultural: Nuevos materialismos. Rowman y Littlefield.

Hickey-Moody, A. C. y Proasi, L. (2021). Nuevo materialismo, etnografía y práctica social comprometida: Pliegues espacio-tiempo y la agencia de la materia. Praxis Educativa, 25(1), 1-14. https://doi.org/10.19137/praxiseducativa-2021-250104

Infante, M. (2018). Cinema experiences at school: assemblages as encounters with subjectivities. International Journal of Inclusive Education. 22(3), 252-267. https://doi.org/10.1080/13603116.2017.1362481

Langer, E., Machado. M., Carpentieri, Y. y Dafunchio, S. (2015). Producir saberes desde la experiencia de un taller audiovisual en contextos de pobreza urbana. Novedades Educativas.

Larrosa, J. (2006). Una lengua para la conversación. Separata Revista Educación y Pedagogía, 18, 29-42.

Masschelein, M. y Simons, J. (2014). En defensa de la escuela. Miño y Dávila.

Mc Ruer, R. (2020). Capacidad corporal obligatoria y existencia discapacitada queer. Papeles del CEIC, 230(2), 1-12. https://doi.org/10.1387/pceic.21903

Murillo, F. J. y Hernández, R. (2014). Liderando escuelas justas para la justicia social. Revista Internacional de Educación para la Justicia Social, 3(2), 13-32.

Nussbaum, M. (2012). Crear capacidades: Propuesta para el desarrollo humano. Paidós. https://doi.org/10.2307/j.ctvt7x63g

Oliver, M. (1990). The politics of disablement. Macmillan. https://doi.org/10.1007/978-1-349-20895-1

Pink, S. (2009). Doing visual ethnography. Routledge. https://doi.org/10.4135/9781446249383 
Prevot-Schapira, M- F. (2001). Fragmentación espacial y social: Conceptos y realidades. Perfiles Latinoamericanos, 19, 33-56.

Redondo, P. (2016). La escuela con los pies en el aire: Hacer escuela entre la emancipación y la desigualdad. [Tesis doctoral, Universidad Nacional de la Plata]. Archivo de la Universidad Nacional de la Plata.

Sánchez-Aranegui, M. D. (2018). O jeito de ser. Arte como um caminho. Revista GEARTE, 5(3), 516-526. https://doi.org/10.22456/2357-9854.88319

Saura-Pérez, Á. (2015). Arte, educación y justicia social. Opción, 31(6), 765-789.

Schwamberger, C., Armella, J., Carpentieri, Y. y Dafunchio, S. (2020). Experiencias que potencian, obras que resisten. Notas sobre la realización audiovisual en la escuela. Artefacto Visual. Revista de Estudios Visuales Latinoamericanos, 5, 64-80.

Schwamberger, C. y Grinberg, S. (2020). Devenir escuela colador: Dinámicas de escolarización de estudiantes con discapacidad en contexto de pobreza urbana de la región metropolitana de Buenos Aires. Praxis Educativa, 24(2), 1-15. https://doi.org/10.19137/praxiseducativa-2020-240204

Scribano, D. (2008). El proceso de investigación social cualitativo. Prometeo.

Thomson, P. (2008). Doing visual research with children and young people. Routledge. https://doi.org/10.4324/9780203870525

Venturiello, M. P. (2016). La trama social de la discapacidad. Biblios.

Watkins, M. (2011). Discipline and learn: Bodies, pedagogy and writing. Sense Publishers.

Youdell, D. (2006). Impossible bodies, impossible selves: Exclusions and student subjectivities. Springer.

\section{Breve CV de la autora}

\section{Cintia Schwamberger}

Becaria Pos-Doctoral del Consejo de Investigaciones Científicas y Técnicas (CONICET) dependiente del Ministerio de Ciencia y Tecnología de la Nación. Desarrolla sus actividades en la Unidad Ejecutora del "Laboratorio de Investigación en Ciencias Humanas" (LICH) de la Universidad Nacional de San Martín. Se desempeña como miembro del equipo de Investigación del Centro de Estudios Desigualdades, Sujetos e Instituciones de la Escuela de Humanidades de UNSAM. Es Doctora por la Universidad de Buenos Aires (UBA) de la Facultad de Filosofía y Letras (FFyL) con mención en Ciencias de la Educación. Licenciada y Profesora de Educación Especial (UNSAM). Miembro del Grupo de Trabajo en Estudios Críticos de la Discapacidad (CLACSO). Asimismo, es Docente de la Escuela de Humanidades (UNSAM).

Email: cintiaschwamberger@gmail.com

ORCID ID: https://orcid.org/0000-0002-2409-0851 